\title{
Protective effects of Yinhuapinggan granule on mice with influenza viral pneumonia
}

\section{Xue-qian Penga, ${ }^{\mathrm{a}, 1}$, Hui-fen Zhou ${ }^{\mathrm{a}, 1}$, Yi-yu Lu ${ }^{\mathrm{b}}$, Jun-kui Chen ${ }^{\mathrm{a}}$, Hai-tong Wan ${ }^{\mathrm{a}, *}$, Yu-yan}

Zhang $^{\mathrm{a}, * *}$

${ }^{a}$ Zhejiang Chinese Medical University, Hangzhou 310053, China

${ }^{\mathrm{b}}$ Center for Disease Control and Prevention of Zhejiang province, Hangzhou 310009, China

\section{A B S T R A C T}

Yinhuapinggan granule (YHPG), a Chinese medicine granule on the basis of Ma-Huang-Tang (Ephedra Decoction) and the clinical experience of Professor Wan Haitong, has been shown to inhibit the growth of influenza virus in vitro. The aim of this study was to investigate the protective effects of YHPG on mice with influenza viral pneumonia and its effects on regulating related inflammatory cytokines in influenza virus A-infected mice. ICR mice were inoculated intranasally with $15 \mathrm{LD}_{50}$ viral dose of influenza virus A/PR/8/34 (H1N1) and treatments with YHPG $(7.5,15$ and $30 \mathrm{~g} / \mathrm{kg}$ ) were orally administrated daily for 5 consecutive days after challenge, respectively. The results showed that mortality rate, lung index, lung histopathological changes, IL- 6 and TNF- $\alpha$ in serum were significantly attenuated in the treatment of YHPG (15 and $30 \mathrm{~g} / \mathrm{kg})$ than those in the IFV control group, while the levels of IL-2 was significantly enhanced. Moreover, the RT-PCR results revealed that YHPG (15 and $30 \mathrm{~g} / \mathrm{kg}$ ) significantly depressed the expressions of IL-1 $\beta$, IFN- $\gamma$ and TNF- $\alpha$ mRNA in lung tissues. Furthermore, the immunohistochemical staining results also revealed that the expression of NF- $\kappa$ B p65 proteins were downregulated when treated with YHPG (15 and 30 $\mathrm{g} / \mathrm{kg}$ ). These results showed YHPG has protective effects on IFV-infected mice, due to its ability of alleviation of lung damage, regulation of the cytokine production via inhibiting the NF- $\mathrm{BB}$ p65 activation, attenuation of systemic and pulmonary inflammatory responses.

Keywords: Yinhuapinggan granule, influenza viral pneumonia, protective effects, inflammatory responses

"Corresponding Author at: Institute of Cardio-Cerebrovascular Diseases, Zhejiang Chinese Medical University, 548 Binwen Road, Hangzhou, China. Tel.: + 860571 86613711, fax: +86 0571 
86613712.

${ }^{* *}$ Corresponding Author at: Institute of Cardio-Cerebrovascular Diseases, Zhejiang Chinese Medical University, 548 Binwen Road, Hangzhou, China. Tel.: + 860571 86613711, fax: +86 0571 86613712.

E-mail: whtong@126.com (H. Wan); yannoo7376@sina.com (Y. Zhang)

${ }^{1}$ These authors contributed equally as principal authors.

\section{Introduction}

Influenza, an acute respiratory viral infectious disease caused by influenza virus, is one of the oldest and most common infections causing substantial morbidity and significant mortality. The recurrent outbreaks of the disease potentially brings about severe consequences for human health and global economy. The 1918-1919 Spanish influenza pandemic as the most severe pandemic outbreak was estimated to have infected one-third of the world's population and caused at least 20-40 million deaths worldwide [1, 2]. It has been reported that approximately $80 \%$ of mortality by influenza virus infection is caused by pneumonia, and the high-risk groups are the elderly and infant $[3,4]$. Based on these facts, much attention has consequently been given to the development of antiviral drugs for the prevention and treatment of this disease.

To date, the M2 ion channel inhibitors and the virus neuraminidase inhibitors have been used for the treatment of influenza virus infections worldwide [5, 6]. However, the occurrence of resistant influenza A viruses and several side effects caused by these drugs have been reported [7, 8]. Therefore, to explore new anti-influenza drugs is important to overcome the limitations of existing anti-influenza virus agents. Although existent evidence tested by randomized trials is sparse and limited, traditional herbal medicines as natural substances for influenza treatment have played an 
important role in the Far East countries, especially in China, Japan and Korea $[9,10]$. For example, Ma-Huang-Tang (Ephedra Decoction), a famous classical formula from the Treatise on Febrizle Disease of Zhang Zhongjing in the Han Dynasty, has been widely used for treating exogenous wind-cold, fever, cough and asthma [11]. It has been reported that Ma-Huang-Tang ( Ephedra Decoction ) shows antipyretic activity clinically $[10,12]$, and alleviative effects against the early phase of influenza virus infection in pharmacological research [13]. Modern clinical research has proved that modified prescriptions of Ephedra decoction work perfectly for the department of internal medicine disease such as influenza, bronchitis, asthma, respiratory infection [14]. Furthermore, in contrast to most antiviral drugs comprised of one single chemical component, traditional Chinese medicine has such advantages as multiple pathways, multitargets, and minimal side effects on the prevention and treatment of influenza, for example, Xiao-qing-long-tang [15]. Therefore, it's crucial to develop possible traditional Chinese medicine for the replacement of anti-influenza drugs.

Yinhuapinggan granule (YHPG), whose major ingredients are based upon classical Ephedra decoction formula, is composed of Puerariae Lobatae Radix, Flos Lonicerae Japonicae, Polygoni Cuspidati Rhizoma, Ephedrae Herba, Armeniacae Semen Amarum and Glycyrrhizae Radix with a ratio of 4:4:4:2:2:1. As an improved formula, YHPG has the good effect of relieving cough, diffusing the lung and releasing exterior, clearing heat and resolving toxins $[16,17]$. Furthermore, YHPG has been proved to inhibit the growth of influenza virus in vitro [18] and to inhibit the influenza virus replication, alleviate the damage of the lung, ameliorate inflammatory responses and adjust for deviant immunologic function of infected mice $[19,20]$. Nevertheless, there is no reports clarified 
the protective effects of YHPG on influenza viral pneumonia in mice. However, several ingredients of YHPG and their constituents have been reported to have antiviral effects on several viruses [10, 21-32]. Therefore, we hypothesize that YHPG can be effective against influenza virus in vivo. In this study, an intranasal influenza virus infection in ICR mouse was utilized as the model to evaluate the protective effects of YHPG and its effects on regulating related inflammatory cytokines.

\section{Materials and Methods}

\subsection{Plant materials and reagents}

As shown in Table 1, Puerariae Lobatae Radix (batch number: 20131001), Flos Lonicerae Japonicae (batch number: 20131101), Polygoni Cuspidati Rhizoma (batch number: 20130801), Herba Ephedrae (batch number: 20130801), Armeniacae Semen Amarum (batch number: 20130801), Glycyrrhizae Radix (batch number: 20131002) were purchased from Hangzhou Huadong Chinese Herbal Medicine Co., Ltd. (Hangzhou, China). These six herbs were identified by Prof. Shengwu Huang, College of Pharmaceutical Science, Zhejiang Chinese Medical University, where voucher specimen was deposited. The crude slices of these drugs conformed to quality standards in Chinese Pharmacopoeia (2010 edition).

Standards of L-ephedrine, D-pseudoephedrine (from Herba Ephedrae), glycyrrhizic acid (from Glycyrrhizae Radix), amygdalin (from Armeniacae Semen Amarum), chlorogenic acid (from Flos Lonicerae Japonicae), puerarin (from Puerariae Lobatae Radix), polygonin and emodin (from Polygoni Cuspidati Rhizoma) were purchased from National Institute for the Control of Pharmaceutical and Biological Products (Beijing, China). Moroxydine was purchased from Lishui Zhenan pharmaceutical Co. Ltd., (Zhejiang, China). Rabbit-anti-mouse polyclonal antibody for 
NF-кB p65 were purchased from Santa Cruz Biotechnology (California, USA). ELISA kits for IL-2, IL-6 and TNF- $\alpha$ were purchased from the Sigma-Aldrich (St. Louis, USA).

\subsection{Preparation of YHPG}

YHPG granules (batch number: 20141101) were produced and supplied by Hangzhou Huadong Medicine Group Kangrun Pharmaceutical Co., Ltd. (Hangzhou, China). Briefly, the powdered Puerariae Lobatae Radix (1000 g) and Flos Lonicerae Japonicae (1000 g) were respectively immersed in $10 \mathrm{~L} 70 \%$ ethanol for $12 \mathrm{~h}$ and extracted using a heating reflux method at $85{ }^{\circ} \mathrm{C}$ for twice ( $1 \mathrm{~h}$ each time). The two collected extractions were mixed, filtered and concentrated under reduced pressure to relative density of $1.14\left(50 \sim 60{ }^{\circ} \mathrm{C}\right)$ as the solution A. The powdered Polygoni Cuspidati Rhizoma (1000 g) was immersed in $10 \mathrm{~L} 80 \%$ ethanol for $12 \mathrm{~h}$ and extracted using a heating reflux method at $85^{\circ} \mathrm{C}$ for twice ( $1 \mathrm{~h}$ each time). Then the extraction was mixed, filtered and concentrated under reduced pressure to relative density of $1.13\left(45 \sim 50{ }^{\circ} \mathrm{C}\right)$ as the solution B. After Herba Ephedrae $(500 \mathrm{~g})$ and Glycyrrhizae Radix $(250 \mathrm{~g})$ were soaked in $12.5 \mathrm{~L}$ water for $2 \mathrm{~h}$, the mixture was decocted with the powdered Armeniacae Semen Amarum (500 g) for three times $(1 \mathrm{~h}$ each time). The decoction was filtered and concentrated to relative density of $1.15\left(50 \sim 60{ }^{\circ} \mathrm{C}\right)$ as the solution C. Subsequently, the solution A was mixed with the solution B and C. After spray drying, the drying powder was thoroughly blent with cornstarch $(150 \mathrm{~g})$ then made into granules, sterilized and encapsulated into bags (6 g per bag).

2.3. High performance liquid chromatography (HPLC) analysis of YHPG

HPLC analysis was performed by using an Agilent 1200 HPLC system, including a G1322A on-line degasser, a G1311A quarternary pump, a G1316A column oven, a G1329A autosampler, a 
G1315B photodiode array detector, controlled by Agilent Rev. B.04.01 chemstation. Chromatographic separation was performed on Agilent Eclipse XDB-C18 column $\left(4.6 \times 250 \mathrm{~mm}^{2}, 5\right.$ $\mu \mathrm{m})$ at $35^{\circ} \mathrm{C}$. The photodiode array detector was set at $210 \mathrm{~nm}$. The mobile phase was a mixture of water containing $0.1 \%$ phosphoric acid (A) and acetonitrile (B). The linear gradients between the time points were as follows: $0-10 \mathrm{~min}$ at $3-9 \% \mathrm{~B}, 10-25 \mathrm{~min}$ at $9-9 \% \mathrm{~B}, 25-40 \mathrm{~min}$ at $9-20 \% \mathrm{~B}$, $40-65 \mathrm{~min}$ at $20-55 \% \mathrm{~B}, 65-75 \mathrm{~min}$ at $55-70 \% \mathrm{~B}, 75-80 \mathrm{~min}$ at $70-3 \% \mathrm{~B}$. The flow rate was maintained at $1.0 \mathrm{~mL} / \mathrm{min}$ and the injection volume was $10 \mu \mathrm{L}$.

\subsection{Virus}

Mouse-adapted influenza virus A/PR/8/34 (H1N1) was donated by Professor Yi-yu Lu from the Zhejiang Center for Disease Control and Prevention, China. The virus was grown in allantoic cavity of 9-days-old embryonated egg for $48 \mathrm{~h}$ at $37{ }^{\circ} \mathrm{C}$. The allantoic fluid was harvested and centrifuged at $1000 \times \mathrm{g}$ for $20 \mathrm{~min}$, and then the resulting supernatant, with haemagglutination titer 1024 , was stored in small portions at $-80{ }^{\circ} \mathrm{C}$. Reed-Muench method was used to determined the $\mathrm{LD}_{50}$ of virus in mice $\left(\mathrm{LD}_{50}=10^{-3.5} / 0.02 \mathrm{~mL}\right)$.

2.5. Animals and preparation of influenza virus infection model

Male special pathogen free ICR mice, weighing $14 \sim 15 \mathrm{~g}$, were obtained from Animal Experimental Center, Zhejiang Chinese Medical University (Laboratory animal certificate: scxk 2008-0016). Animals were housed plastic cages in an air-conditioned room at $23 \pm 2{ }^{\circ} \mathrm{C}$ with a relative humidity of $55 \pm 10 \%$ under a $12 \mathrm{~h}$ light/dark cycle, fed a standard laboratory diet and given water ad libitum. Animal experiments were carried out in accordance with local guidelines for the care of laboratory animals of Animal Experimental Center, Zhejiang Chinese Medical University, 
and were approved by the ethics committee for research on laboratory animal use of the institution.

Mice were randomly divided into six groups (10 mice each group): Normal control group (Normal-C), IFV-infected control group (IFV-C), Moroxydine treated group, low, moderate and high dose of YHPG treated group. Mice were intranasally inoculated with $15 \mathrm{LD}_{50}$ doses of influenza virus in a volume of $20 \mu \mathrm{l}$ sterile saline except normal control group. After 2 hours of inoculation, YHPG $(7.5,15$, and $30 \mathrm{~g} / \mathrm{kg})$ or moroxydine $(0.25 \mathrm{~g} / \mathrm{kg})$ was orally administered to experimental groups daily for 5 days, while mice in the normal and IFV-infected control group were treated with normal saline at the same intervals. The low dose of YHPG for mouse study was equivalent to the human dosage in clinical practice, while the moderate and high dose of YHPG were twice and four times of the human clinical dosage, respectively.

\subsection{Survival rate}

Mice were randomly divided into six groups (10 mice each group): Normal control group (Normal-C), IFV-infected control group (IFV-C), Moroxydine treated group, low, moderate and high dose of YHPG treated group. Mice were intranasally inoculated with $15 \mathrm{LD}_{50}$ doses of influenza virus in a volume of $20 \mu \mathrm{l}$ sterile saline except normal control group. After 2 hours of inoculation, YHPG $(7.5,15$, and $30 \mathrm{~g} / \mathrm{kg})$ or moroxydine $(0.25 \mathrm{~g} / \mathrm{kg})$ was orally administered to experimental groups daily for 7 days, while mice in the normal and IFV-infected control group were treated with normal saline at the same intervals. Ten mice from each group was observed daily for $15 \mathrm{~d}$ after IFV infection. In addition, clinical signs and time of death were recorded daily.

2.7. Biochemical analysis

On day 6 ( $5 \mathrm{~d}$ after infection), ten mice in each group were sacrificed to calculate lung index. 
Then the lung were harvested and divided into two parts (the right lung for histopathology and immunohistochemical analysis, the left lung for RT-PCR). Blood samples were collected and centrifuged at $3000 \mathrm{~g}$ for $20 \mathrm{~min}$ to obtain serum. The levels of IL-2, IL-6 and TNF- $\alpha$ in serum were determined by ELISA. The lung index and inhibition rate of lung index were used as an indicator of pneumonia [33], according to the following equation:

Lung index $=$ Wet weight $(\mathrm{g}) /$ Body weight $(\mathrm{g}) \times 100 \%$

Inhibition rate of lung index $=$ (the average lung index of IFV-infected group-the average lung index of experimental group) / the average lung index of IFV-infected group $\times 100 \%$

\subsection{Real-Time PCR Analysis}

RT-PCR was used to assess the levels of IL- $1 \beta$, IFN- $\gamma$ and TNF- $\alpha$ mRNA in lung tissues. The left lungs were respectively homogenized and centrifuged at $4000 \mathrm{rpm}$ for $10 \mathrm{~min}$ at $4{ }^{\circ} \mathrm{C}$. Total RNA in the supernatant were extracted with RNA Qiagen reagent (QIAGEN, Germany), dissolved in DEPC- $\mathrm{H}_{2} \mathrm{O}(30 \mu \mathrm{L})$. The total RNA was reverse transcribed with PrimeScript ${ }^{\mathrm{TM}}$ RT Master Mix Kit (TaKaRa, Japan). The primers were synthesized according to the literature [34] and PCR primer used are described in Table 2. PCR reactions were carried out in $20 \mu \mathrm{L}$ final volume which contained 10 $\mu$ mol/L each primer $(0.8 \mu \mathrm{L}), 1 \mu \mathrm{L}$ template DNA, $2 \times$ SYBR Green $(10 \mu \mathrm{L})$, and RNase-free $\mathrm{H}_{2} \mathrm{O}$ $(7.4 \mu \mathrm{L})$. The reaction conditions were as follows: $95{ }^{\circ} \mathrm{C} 2 \mathrm{~min}$, followed by $95{ }^{\circ} \mathrm{C} 15 \mathrm{~s}, 55{ }^{\circ} \mathrm{C} 35 \mathrm{~s}$ for 40 cycles using a QuanStudio 12K Flex Real time PCR (ABI, USA). The relative quantification of PCR products was performed according to the $2^{-\Delta \Delta C t}$ method [35]. The fold change in target gene cDNA relative to the GAPDH internal control was determined using the following formula:

Fold change $=2^{-\Delta \Delta \mathrm{CT}}$, where $\Delta \Delta \mathrm{Ct}=\left(\mathrm{Ct}_{\text {target gene }}-\mathrm{Ct} \mathrm{GAPDH}_{\mathrm{G}}\right)-\left(\mathrm{Ct}_{\text {control }}-\mathrm{Ct} \mathrm{GAPDH}\right)$. 


\subsection{Histopathology of lungs}

The right lung lobes were washed with normal saline, fixed with $10 \%$ formaldehyde solution. Tissue sections were then embedded in low-melting point paraffin, cut at $3 \mu \mathrm{m}$ thickness, and stained with hematoxylin and eosin (H\&E). Slides of lungs were observed in a double-blinded fashion under light microscopy.

\subsection{Detection of NF- $\kappa B$ p65 expression}

For the immunohistochemical analysis, the $3 \mu \mathrm{m}$ thick lung sections were treated with primary antibody against NF-kB p65 (rabbit-anti-mouse, 1:100) at room temperature for $60 \mathrm{~min}$. The lung sections were washed 3 times in PBS for 5 min each and then incubated with secondary antiserum (EnVision Two-Step kit, Denmark) for $40 \mathrm{~min}$ at room temperature. Subsequently, the lung sections were washed 3 times with PBS and then incubated with diaminobenzidine (DAB) and Hematoxylin staining solution (Harris) for 2-3 min, dehydrated using graded alcohols and xylene. Finally, the brown reaction product was observed at 200 amplification times of light microscope. The positive cells showed yellow or brown articles or clumps in the cytoplasm and nucleus. Furthermore, the integrated optical density (IOD) of NF- $\kappa \mathrm{B}$ p65 were measured by averaging 5 microscopic fields (200 magnification) with use of Image-ProPlus 6.0 software (Media Cybernetics, USA).

\subsection{Statistical analysis}

All statistical analyses were performed using SPSS 19.0 and all results were presented as mean \pm S.D. The significance of differences among multiple group comparisons were performed using one-way analysis of variance (ANOVA). Differences were considered statistically significant when $p<0.05$. 


\section{Results}

\subsection{HPLC profile of YHPG}

As compared with standard reference compounds, eight effective constituents of YHPG, including L-ephedrine, D-pseudoephedrine, chlorogenic acid, amygdalin, puerarin, polygonin, glycyrrhizic acid and emodin, were analyzed by HPLC (Fig. 1-2). The contents of these compounds in YHPG were observed as $0.73 \mathrm{mg} / \mathrm{g}, 0.407 \mathrm{mg} / \mathrm{g}, 1.92 \mathrm{mg} / \mathrm{g}, 6.37 \mathrm{mg} / \mathrm{g}, 4.35 \mathrm{mg} / \mathrm{g}, 1.79 \mathrm{mg} / \mathrm{g}$, $0.692 \mathrm{mg} / \mathrm{g}, 0.329 \mathrm{mg} / \mathrm{g}$, respectively.

\subsection{Efficacies of YHPG in IFV-induced mice}

The experimental mice were monitored for 2 weeks, and almost all of the mice in the IFV control group died within 11 days after infection and none of the mice died in the normal control group (Fig. 3). Mice in the IFV group presented clinical signs such as inactive, ruffled fur, hunched posture, lack of appetite and respiratory distress. Although the similar clinical features were observed in the treated group, the signs were better than that in the IFV control group. Furthermore, compared with IFV control group, treatment with YHPG (15 and $30 \mathrm{~g} / \mathrm{kg}$ ) or moroxydine significantly reduced mortality, prolonged life span and increased the survival time of infected mice $(P<0.01$ and $P<0.05)($ Fig. 3).

\subsection{Effects of YHPG on influenza viral pneumonia}

Lung index and inhibition rate of lung index were calculated to assess influenza viral pneumonia. As shown in Fig. 3, lung index was significantly higher in the IFV-infected group than in the normal control group after influenza virus infection $(P<0.01)$. Treatment with YHPG (15 and 30 $\mathrm{g} / \mathrm{kg}$ ) or moroxydine significantly decreased lung index $(P<0.01)$, and increased the inhibition rate 
of lung index (Table 3). However, YHPG $(7.5 \mathrm{~g} / \mathrm{kg}$ ) had no significant effect on lung index. These results indicate that YHPG (15 and $30 \mathrm{~g} / \mathrm{kg}$ ) can inhibit pneumonia induced by influenza virus.

\subsection{Effect of YHPG Treatment on IFV-induced lung pathological changes}

Lung pathological changes from treated and untreated mice with IFV infection were shown (Fig. 4A-F). The mice in the control group showed no obvious histological changes (Fig. 4A). In the IFV-infected group, the lungs of mice showed the presence of necrotic bronchial and bronchiolar epithelium, hemorrhage, thickening of the alveolar and marked infiltration of inflammatory cells (Fig. 4B). Compared with the IFV control group, the IFV-induced lung inflammation was significantly reduced through treatment with YHPG $(15$ and $30 \mathrm{~g} / \mathrm{kg})$ or moroxydine $(0.25 \mathrm{~g} / \mathrm{kg})(\mathrm{Fig}$. 4C and Fig. 4E-F). However, treatment with YHPG $(7.5 \mathrm{~g} / \mathrm{kg})$ was as similar in histological changes as the IFV control group (Fig. 4D). This results indicates that treatment of YHPG (15 and $30 \mathrm{~g} / \mathrm{kg}$ ) can ameliorate the lung damage of in IFV-infected mice.

\subsection{Effect of YHPG on cytokines production in IFV-infected mice}

To investigate the effects of YHPG on the regulation of cytokine productions, the levels of three inflammatory cytokines were measured from the mice serum. As shown in Fig. 5, IL-6 and TNF- $\alpha$ levels in serum were significantly increased after IFV infection, whereas the IL-2 level was significantly decreased compared with the normal control group. Oral administration of $7.5 \mathrm{~g} / \mathrm{kg}$ to $30 \mathrm{~g} / \mathrm{kg}$ YHPG significantly decreased the production of IL-6 and TNF- $\alpha$ in serum and administration of $15 \mathrm{~g} / \mathrm{kg}$ to $30 \mathrm{~g} / \mathrm{kg}$ YHPG increased the production of serum IL-2 compared with the IFV control group.

3.6. Expression of IL-1 $\beta$, IFN- $\gamma$ and TNF- $\alpha$ in lung tissues by Real-Time PCR 
According to Fig. 6., in IFV control group, the expression of IFN- $\gamma$ mRNA was significantly downregulated, while the expression of IL- $1 \beta$ and TNF- $\alpha$ mRNA were markedly upregulated compared with normal control group $(P<0.01)$. In the treatment group of YHPG (15 and $30 \mathrm{~g} / \mathrm{kg})$, the expression of IFN- $\gamma$ mRNA was significantly upregulated, while the expression of IL-1 $\beta$ and TNF- $\alpha$ mRNA were markedly downregulated compared with IFV-infected group $(P<0.01)$.

\subsection{Effect of YHPG on NF- $\mathrm{B}$ p 65 expression}

The expressions of NF- $\mathrm{BB}$ p65 proteins in the lung tissues were delineated and quantified (Fig. 7 and Fig. 8). We measured the IOD of NF- $\mathrm{kB}$ p65 and calculated the mean values and SDs. Compared with normal control group, the IOD of NF- $\mathrm{BB}$ p65 significantly increased in the IFV-infected group $(P<0.01)$. In the YHPG $(15$ and $30 \mathrm{~g} / \mathrm{kg})$ treated mice, the IOD of NF- $\mathrm{kB}$ p65 was significantly lower than that in the IFV-infected group $(P<0.05$ and $P<0.01)$. However, no significant difference was observed between the YHPG $(7.5 \mathrm{~g} / \mathrm{kg})$ group and IFV-infected group.

\section{Discussion}

In this study, the effects of YHPG on mice infected by H1N1 virus were investigated. Our present study indicated that YHPG (15 and $30 \mathrm{~g} / \mathrm{kg}$ ) significantly reduced mortality, prolonged life span and increased the survival time of infected mice. The clinical signs were alleviated in the YHPG-treated group. To evaluate the severity of pneumonia, lung index and pathological changes in lung tissues were used in our experiment. A number of studies have shown that lung index, which is an indicator of the severity of pneumonia, has an evident increase in the early phase of influenza virus infection [36-38]. Our research showed that remarkable decreases in the lung indexes were observed in YHPG (15 and 30g/kg) group. In addition, excessive immune response, associating with 
pathological changes in lung tissues, is believed to be an evidence for influenza-mediated death [39, 40]. The pathological analysis demonstrated that there were obviously necrotic bronchial, thickening of the alveolar and marked infiltration of inflammatory cells in the IFV-infected group, which was in accordance with precious studies [41]. When mice were treated with YHPG (15 and $30 \mathrm{~g} / \mathrm{kg}$ ), the histological changes in lung tissues were significantly reduced. These results indicated that treatment with YHPG could effectively alleviate the lung lesions and inflammation of mice infected with influenza virus.

The immune system plays a crucial role in regulating the host response to control inflammation and prevent excessive injury [42]. After infection, exaggerated inflammatory responses, which in turn resulted in the overproduction of inflammatory cytokines and chemokines, were likely to generate pneumonia [43, 44]. Therefore, there is a strong correlation between cytokines and pneumonia. IL-1 is identified as a primary target for therapeutic intervention in the pathogenesis and treatment of inflammatory diseases [45]. TNF- $\alpha$, one of the most prominent inflammatory cytokines in influenza A virus infection, has a significant role in priming epithelial cells for higher cytokine and chemokine production [46]. In addition, TNF- $\alpha$ level is directly related with the severity of histologic lung lesions after infection [47]. At the same time, patients with pneumonia was also detected to have high level of pro-inflammatory cytokine IL-6, which was demonstrated to have a positive correlation with lung inflammation [48, 49]. IL-2 is a T-helper 1 (Th1) cytokine that stimulates IFN- $\gamma$ secretion, which is crucial for viral clearance [50]. IFN- $\gamma$, which is produced by $\mathrm{T}$ cells and natural killer cells, protects infected mice from death at the early stage of influenza virus infection and ameliorates the severity of inflammation and lung damage [51, 52]. Moreover, the 
overproduction of cytokines are the main reason for lung tissue damage [53]. In our study, treatment with YHPG (7.5 g/kg to $30 \mathrm{~g} / \mathrm{kg}$ ) significantly decreased IL-6 and TNF- $\alpha$ levels, whereas the level of IL-2 was significantly increased at doses of 15 or $30 \mathrm{~g} / \mathrm{kg}$. In addition, our results demonstrated that the expression levels of IL- $1 \beta$ and TNF- $\alpha$ mRNA were remarkably increased while the expression levels of IFN- $\gamma$ mRNA were significantly decreased in lung tissues after infection [34]. In contrast, YHPG at doses of 15 or $30 \mathrm{~g} / \mathrm{kg}$ dramaticlly decreased the expression levels of IL- $1 \beta$ and TNF- $\alpha$ mRNA and increased the expression levels of IFN- $\gamma$ mRNA in comparision with IFV-infected group. These resluts indicated that YHPG could be effective in treatment to mice with influenza viral pneumonia, which correlated with the regulation of systemic inflammatory cytokine levels. The regulating effects of YHPG on systemic inflammatory cytokine levels was beneficial to alleviate the systemic and pulmonary inflammatory responses.

It is well-known that rapid production of inflammatory cytokines is regulated by a transcription factor NF- $\mathrm{KB}$, which plays a crucial role in inducing transcription of inflammatory genes $[54,55]$. The activation of NF- $\mathrm{KB}$ is widely involved in inflammatory diseases [56]. In this study, immunohistochemical analysis showed that NF- $\mathrm{kB}$ p65 was activated after infection. Compare with normal control group, the expressions of NF- $\mathrm{kB}$ p65 in the IFV-infected group were markedly increased as reported in previous studies [33, 57]. Treatment with YHPG (15 and $30 \mathrm{~g} / \mathrm{kg}$ ) after infection significantly decreased the expressions of NF- $\mathrm{kB}$ p65 in comparision to that observed in the IFV-infected group, suggesting that the protective effects of YHPG on IFV-infected mice were partly connected with the inhibition of the expressions of NF-kB p65.

YHPG is a Chinese medicine granule whose major ingredients are based upon the classical 
MHT formula. Our previous studies have demonstrated that YHPG has obvious antiviral, anti-inflammatory and antitussive effects in mice and rats [17-20]. The HPLC analysis clearly revealed the presence of the major constituents of YHPG (Fig. 1). From literatures, we found that the main component of Flos Lonicerae Japonicae, chlorogenic acid, has shown significant antiviral activity in vitro [26, 58]. Glycyrrhizin, which is an active component of Glycyrrhizae Radix, may protect mice infected with lethal doses of influenza virus through the induction of IFN- $\gamma$ production by $\mathrm{T}$ cells [59], and has been reported to inhibit influenza A virus uptake into the cell [30]. Further, the main component of Polygoni Cuspidati Rhizoma, emodin, inhibits the replication of influenza virus H1N1 in A549 cells [32]. So, we hypothesize that chlorogenic acid, glycyrrhizin and emodin may be the active components of YHPG against influenza virus. However, additional investigations are required to identify the possible anti-influenza bioactive components in YHPG.

\section{Conclusion}

In summary, our results demonstrated that YHPG had a protective effect on IFV-infected mice, which might be associated with alleviation of lung injury, regulation of the cytokine production via inhibiting the NF- $\mathrm{KB}$ p65 activation, attenuation of systemic and pulmonary inflammatory responses. These findings were useful for the further investigation of the mechanisms of YHPG and provide a new choice for the treatment of influenza virus infection.

\section{Acknowledgment}

This work was supported by a grant from Zhejiang Provincial Natural Science Foundation (No. LZ14H270001) and Zhejiang province key subject of traditional Chinese medicine (2012-XK-A06). We thank Professor Yi-yu Lu for technical help in the animal experiment and helpful discussion of 
this work.

\section{References}

[1] Murray CJ, Lopez AD, Chin B, Feehan D, Hill KH. Estimation of potential global pandemic influenza mortality on the basis of vital registry data from the 1918-20 pandemic: a quantitative analysis. Lancet 2006;368:2211-8.

[2] Azizi MH, Raees Jalali GA, Azizi F. A history of the 1918 Spanish influenza pandemic and its impact on Iran. Arch Iran Med 2010;13:262-5.

[3] Nicholson KG, Aoki FY, Osterhaus AD, Trottier S, Carewicz O, Mercier CH, et al. Efficacy and safety of oseltamivir in treatment of acute influenza: a randomised controlled trial. Neuraminidase Inhibitor Flu Treatment Investigator Group. Lancet 2000;355:1845-50.

[4] Matias G, Taylor R, Haguinet F, Schuck-Paim C, Lustig R, Shinde V. Estimates of mortality attributable to influenza and RSV in the United States during 1997-2009 by influenza type or subtype, age, cause of death, and risk status. Influenza Other Respi Viruses 2014;8:507-15.

[5] De Clercq E. Antiviral agents active against influenza A viruses. Nat Rev Drug Discov 2006;5:1015-25.

[6] Moscona A. Medical management of influenza infection. Annu Rev Med 2008;59:397-413.

[7] Nitsch-Osuch A, Brydak LB. Influenza viruses resistant to neuraminidase inhibitors. Acta Biochim Pol 2014;61:505-8.

[8] Hayden F. Developing new antiviral agents for influenza treatment: what does the future hold? Clin Infect Dis 2009;48 Suppl 1:S3-13.

[9] Guo R, Pittler MH, Ernst E. Complementary medicine for treating or preventing influenza or influenza-like illness. Am J Med 2007;120:923-9.e3.

[10] Kubo T, Nishimura H. Antipyretic effect of Mao-to, a Japanese herbal medicine, for treatment of type A influenza infection in children. Phytomedicine 2007;14:96-101.

[11] Yang X, Peng WB, Yue XQ. Syndrome differentiation and treatment of Taiyang disease in Shanghan Lun. Zhong Xi Yi Jie He Xue Bao 2009;7:171-4.

[12] Nabeshima S, Kashiwagi K, Ajisaka K, Masui S, Takeoka H, Ikematsu H, et al. A randomized, controlled trial comparing traditional herbal medicine and neuraminidase inhibitors in the treatment of seasonal influenza. Journal of Infection and Chemotherapy 2012;18:534-43.

[13] Nagai T, Kataoka E, Aoki Y, Hokari R, Kiyohara H. Alleviative Effects of a Kampo (a Japanese Herbal) Medicine "Maoto (Ma-Huang-Tang)" on the Early Phase of Influenza Virus Infection and Its Possible Mode of Action. Evid Based Complement Alternat Med 2014;2014:187036.

[14] Zhang BG, Liu QF. Modern pharmacodynamic research and clinical application of Ephedra decoction. Chinese Traditional Patent Medicine 2007;29:415-22.

[15] Wang C, Cao B, Liu QQ, Zou ZQ, Liang ZA, Gu L, et al. Oseltamivir compared with the Chinese traditional therapy maxingshigan-yinqiaosan in the treatment of H1N1 influenza: a randomized trial. Ann Intern Med 2011;155:217-25.

[16] He Y, Yu DJ, Zhang YY, Yang JH, Zhou HF, Wan HT. Anti-tussive effect experiment of Yinhua Pinggan granule. Chinese Archives of Traditional Chinese Medicine 2014;32:2060-61.

[17] Wan HT, Yu DJ, Lei Y, Bai HB, Yang JH, Bie XD. Anti-inflammatory and analgesic effects 
experiment of Jin-Ping-Gan granule. Pharmacology and Clinics of Chinese Materia Medica 2002;18:39-40.

[18] Peng HQ, Xu ZM, Wan HT, Yu DJ. Inhibitory effect of Jin-Ping-Gan granule on influenza virus. Zhejiang Journal of Traditional Chinese Medicine 2005;12:87-8.

[19] Peng XQ, He Y, Zhou HF, Zhang YY, Chen JK, Lu YY, et al. Effects of Yinghuapinggan granule against influenza A/H1N1 virus in vivo. Zhongguo Zhong yao za zhi 2015;40:40-5.

[20] Peng XQ, Zhou HF, Zhang YY, Yang JH, Wan HT, He Y. Antiviral effects of Yinhuapinggan granule against influenza virus infection in the ICR mice model. J Nat Med 2015, doi: 10.1007/s11418-015-0939-z.

[21] Mantani N, Andoh T, Kawamata H, Terasawa K, Ochiai H. Inhibitory effect of Ephedrae herba, an oriental traditional medicine, on the growth of influenza A/PR/8 virus in MDCK cells. Antiviral Res 1999;44:193-200.

[22] Fiore C, Eisenhut M, Krausse R, Ragazzi E, Pellati D, Armanini D, et al. Antiviral effects of Glycyrrhiza species. Phytother Res 2008;22:141-8.

[23] Shi Y, Wu D, Sun Z, Yang J, Chai H, Tang L, et al. Analgesic and uterine relaxant effects of isoliquiritigenin, a flavone from Glycyrrhiza glabra. Phytother Res 2012;26:1410-7.

[24] Chen KT, Zhou WL, Liu JW, Zu M, He ZN, Du GH, et al. Active neuraminidase constituents of Polygonum cuspidatum against influenza $\mathrm{A}(\mathrm{H} 1 \mathrm{~N} 1)$ influenza virus. Zhongguo Zhong yao za zhi 2012;37:3068-73.

[25] Kashiwada Y, Omichi Y, Kurimoto S, Shibata H, Miyake Y, Kirimoto T, et al. Conjugates of a secoiridoid glucoside with a phenolic glucoside from the flower buds of Lonicera japonica Thunb. Phytochemistry 2013;96:423-9.

[26] Wang GF, Shi LP, Ren YD, Liu QF, Liu HF, Zhang RJ, et al. Anti-hepatitis B virus activity of chlorogenic acid, quinic acid and caffeic acid in vivo and in vitro. Antiviral Res 2009;83:186-90.

[27] Kuo KK, Chang JS, Wang KC, Chiang LC. Water extract of Glycyrrhiza uralensis inhibited enterovirus 71 in a human foreskin fibroblast cell line. Am J Chin Med 2009;37:383-94.

[28] Cinatl J, Morgenstern B, Bauer G, Chandra P, Rabenau H, Doerr HW. Glycyrrhizin, an active component of liquorice roots, and replication of SARS-associated coronavirus. Lancet 2003;361:2045-6.

[29] Harada S. The broad anti-viral agent glycyrrhizin directly modulates the fluidity of plasma membrane and HIV-1 envelope. Biochem J 2005;392:191-9.

[30] Wolkerstorfer A, Kurz H, Bachhofner N, Szolar OH. Glycyrrhizin inhibits influenza A virus uptake into the cell. Antiviral Res 2009;83:171-8.

[31] Feng Yeh C, Wang KC, Chiang LC, Shieh DE, Yen MH, San Chang J. Water extract of licorice had anti-viral activity against human respiratory syncytial virus in human respiratory tract cell lines. $\mathrm{J}$ Ethnopharmacol 2013;148:466-73.

[32] Lin CJ, Lin HJ, Chen TH, Hsu YA, Liu CS, Hwang GY, et al. Polygonum cuspidatum and its active components inhibit replication of the influenza virus through toll-like receptor 9-induced interferon beta expression. PLoS One 2015;10:e0117602.

[33] Wu XN, Yu CH, Cai W, Hua J, Li SQ, Wang W. Protective effect of a polyphenolic rich extract from Magnolia officinalis bark on influenza virus-induced pneumonia in mice. J Ethnopharmacol 2011;134:191-4.

[34] Lu NN, Liu Q, Gu LG, Ge SJ, Wu J, Ze-Ji Q, et al. Gene Expression Profiles Underlying Selective 
T-Cell-Mediated Immunity Activity of a Chinese Medicine Granule on Mice Infected with Influenza Virus H1N1. Evid Based Complement Alternat Med 2014;2014:976364.

[35] Livak KJ, Schmittgen TD. Analysis of relative gene expression data using real-time quantitative PCR and the 2(-Delta Delta C(T)) Method. Methods 2001;25:402-8.

[36] Barnard DL. Animal models for the study of influenza pathogenesis and therapy. Antiviral Res 2009;82:A110-22.

[37] Yu CH, Yan YL, Wu XN, Zhang B, Wang W, Wu QF. Anti-influenza virus effects of the aqueous extract from Mosla scabra. J Ethnopharmacol 2010;127:280-5.

[38] Dai WP, Li G, Li X, Hu QP, Liu JX, Zhang FX, et al. The roots of Ilex asprella extract lessens acute respiratory distress syndrome in mice induced by influenza virus. J Ethnopharmacol 2014;155:1575-82.

[39] Maines TR, Jayaraman A, Belser JA, Wadford DA, Pappas C, Zeng H, et al. Transmission and pathogenesis of swine-origin $2009 \mathrm{~A}(\mathrm{H} 1 \mathrm{~N} 1)$ influenza viruses in ferrets and mice. Science 2009;325:484-7.

[40] Peiris JS, Hui KP, Yen HL. Host response to influenza virus: protection versus immunopathology. Curr Opin Immunol 2010;22:475-81.

[41] Li YC, Peng SZ, Chen HM, Zhang FX, Xu PP, Xie JH, et al. Oral administration of patchouli alcohol isolated from Pogostemonis Herba augments protection against influenza viral infection in mice. Int Immunopharmacol 2012;12:294-301.

[42] La Gruta NL, Kedzierska K, Stambas J, Doherty PC. A question of self-preservation: immunopathology in influenza virus infection. Immunol Cell Biol 2007;85:85-92.

[43] Garigliany MM, Habyarimana A, Lambrecht B, Van de Paar E, Cornet A, van den Berg T, et al. Influenza A strain-dependent pathogenesis in fatal $\mathrm{H} 1 \mathrm{~N} 1$ and $\mathrm{H} 5 \mathrm{~N} 1$ subtype infections of mice. Emerg Infect Dis 2010;16:595-603.

[44] Kobasa D, Jones SM, Shinya K, Kash JC, Copps J, Ebihara H, et al. Aberrant innate immune response in lethal infection of macaques with the 1918 influenza virus. Nature 2007;445:319-23.

[45] Dinarello CA. Interleukin-1 in the pathogenesis and treatment of inflammatory diseases. Blood 2011;117:3720-32.

[46] Veckman V, Osterlund P, Fagerlund R, Melen K, Matikainen S, Julkunen I. TNF-alpha and IFN-alpha enhance influenza-A-virus-induced chemokine gene expression in human A549 lung epithelial cells. Virology 2006;345:96-104.

[47] Hussell T, Pennycook A, Openshaw PJ. Inhibition of tumor necrosis factor reduces the severity of virus-specific lung immunopathology. Eur J Immunol 2001;31:2566-73.

[48] Choussat R, Montalescot G, Collet J, Jardel C, Ankri A, Fillet A, et al. Effect of prior exposure to Chlamydia pneumoniae, Helicobacter pylori, or cytomegalovirus on the degree of inflammation and one-year prognosis of patients with unstable angina pectoris or non-Q-wave acute myocardial infarction. Am J Cardiol 2000;86:379-84.

[49] Shin K, Wakabayashi H, Yamauchi K, Teraguchi S, Tamura Y, Kurokawa M, et al. Effects of orally administered bovine lactoferrin and lactoperoxidase on influenza virus infection in mice. J Med Microbiol 2005;54:717-23.

[50] Yeo JM, Lee HJ, Kim JW, Lee JB, Park SY, Choi IS, et al. Lactobacillus fermentum CJL-112 protects mice against influenza virus infection by activating T-helper 1 and eliciting a protective immune response. Int Immunopharmacol 2014;18:50-4. 
[51] Weiss ID, Wald O, Wald H, Beider K, Abraham M, Galun E, et al. IFN-gamma treatment at early stages of influenza virus infection protects mice from death in a NK cell-dependent manner. $\mathrm{J}$ Interferon Cytokine Res 2010;30:439-49.

[52] Wiley JA, Cerwenka A, Harkema JR, Dutton RW, Harmsen AG. Production of interferon-gamma by influenza hemagglutinin-specific CD8 effector T cells influences the development of pulmonary immunopathology. Am J Pathol 2001;158:119-30.

[53] Hayden FG, Fritz R, Lobo MC, Alvord W, Strober W, Straus SE. Local and systemic cytokine responses during experimental human influenza A virus infection. Relation to symptom formation and host defense. J Clin Invest 1998;101:643-9.

[54] Amigo M, Paya M, Braza-Boils A, De Rosa S, Terencio MC. Avarol inhibits TNF-alpha generation and NF-kappaB activation in human cells and in animal models. Life Sci 2008;82:256-64.

[55] Lawrence T, Fong C. The resolution of inflammation: anti-inflammatory roles for NF-kappaB. Int $\mathrm{J}$ Biochem Cell Biol 2010;42:519-23.

[56] Karin M, Yamamoto Y, Wang QM. The IKK NF-kappa B system: a treasure trove for drug development. Nat Rev Drug Discov 2004;3:17-26.

[57] Li L, Yu CH, Ying HZ, Yu JM. Antiviral effects of modified dingchuan decoction against respiratory syncytial virus infection in vitro and in an immunosuppressive mouse model. J Ethnopharmacol 2013;147:238-44.

[58] Hu KJ, Wang YH, Wang D. The inhibited effect of chlorogenic acid from the honeysuckle on virus in vitro. Information on Traditional Chinese Medicine 2010;27:27-8.

[59] Utsunomiya T, Kobayashi M, Pollard RB, Suzuki F. Glycyrrhizin, an active component of licorice roots, reduces morbidity and mortality of mice infected with lethal doses of influenza virus. Antimicrob Agents Chemother 1997;41:551-6. 


\section{Table 1}

Component herbs of YHPG.

\begin{tabular}{lllll}
\hline Pharmaceutical name & Botanical plant name & Family & Weight $(\mathrm{g})$ & Used part \\
\hline Flos Lonicerae Japonicae & Lonicera japonica Thunb. & Caprifoliaceae & 10 & Flower bud \\
Herba Ephedrae & Ephedra sinica Stapf. & Ephedraceae & 5 & Aerial part \\
Puerariae Lobatae Radix & Pueraria lobata (Willd.) Ohwi & Lamiaceae & 10 & Radix \\
Polygoni Cuspidati Rhizoma & Polygonum cuspidatum Sieb. et Zucc. & Polygonaceae & 10 & Root and Rhizome \\
Armeniacae Semen Amarum & Prunus armeniaca L. var. ansu. Maxim. & Rosaceae & 5 & Fruit \\
Glycyrrhizae Radix & Glycyrrhiza uralensis Fischer & Leguminosae & 2.5 & Root and Stolon \\
\hline
\end{tabular}

\section{Table 2}

Primer sequences used for RT-PCR analysis.

\begin{tabular}{cccc}
\hline Gene & Product size & Forward (5'-3') & Reverse (5'-3') \\
\hline IL-1 $\beta$ & $130 \mathrm{bp}$ & TCAGGCAGGCAGTATCACTC & AGGATGGGCTCTTCTTCAA \\
IFN- $\gamma$ & $179 \mathrm{bp}$ & AGGCCATCAGCAACAACATA & TGAGCTCATTGAATGCTTGG \\
TNF- $\alpha$ & $133 \mathrm{bp}$ & CCAAAGGGATGAGAAGTTCC & CTCCACTTGGTGGTTTGCTA \\
GAPDH & $141 \mathrm{bp}$ & GCAAGTTCAACGGCACAG & CGCCAGTAGACTCCACGAC \\
\hline
\end{tabular}

\section{Table 3}

The inhibition rate of lung index in mice treated with YHPG or moroxydine $(n=10)$.

\begin{tabular}{ccc}
\hline Groups & Dose $(\mathrm{g} / \mathrm{kg})$ & Inhibition rate of lung index $(\%)$ \\
\hline Normal-C & - & - \\
IFV-C & - & - \\
Moroxydine & 0.25 & 22.4 \\
YHPG & 7.5 & 7.2 \\
YHPG & 15 & 20.4 \\
YHPG & 30 & 30.3 \\
\hline
\end{tabular}


Figure captions

Fig. 1. 2D HPLC chromatograms of eight effective constituents inYHPG at $210 \mathrm{~nm}$. 1. L-ephedrine; 2.

D-pseudoephedrine; 3. chlorogenic acid; 4. amygdalin; 5. puerarin; 6. polygonin; 7. glycyrrhizic acid and 8. emodin.

Fig. 2. Chemical structures of eight effective constituents in YHPG.

Fig. 3. Survival rate of YHPG treatment on IFV-infected mice ( $\mathrm{n}=10$ in each group). ${ }^{\# \#} \mathrm{P}<0.01$ vs. Normal-C, ${ }^{*} \mathrm{P}<0.05$, ${ }^{* *} \mathrm{P}<0.01$ vs. IFV-C.

Fig. 4. Change of YHPG treatment on the lung index of IFV-infected mice ( $n=10$ in each group). Lung index was significantly decreased in YHPG-treated groups as compared to the IFV control group. ${ }^{\#} P<0.01$ vs. Normal-C, ${ }^{* *} P<0.01$ and ${ }^{*} P<0.05$ vs. IFV-C.

Fig. 5. Effects of YHPG on IFV-induced lung histopathogic changes. (A) Normal control group; (B) IFV control group; (C) infected mice treated with moroxydine $(0.25 \mathrm{~g} / \mathrm{kg})$; (D) infected mice treated with YHPG $(7.5 \mathrm{~g} / \mathrm{kg})$; (E) infected mice treated with YHPG (15 g/kg); and (F) infected mice treated with YHPG (30 g/kg). Representative histological section of the lungs was stained by hematoxylin and eosin (magnification $100 \times$ ).

Fig. 6. Effect of YHPG treatment on the production of (A) IL-2, (B) IL-6 and (C) TNF- $\alpha$ in the serum of IFV-infected mice (n=10 in each group). ${ }^{\#} \mathrm{P}<0.01$ vs. Normal-C, ${ }^{*} \mathrm{P}<0.05,{ }^{* *} \mathrm{P}<0.01$ vs. IFV-C.

Fig. 7. Effect of YHPG treatment on the expression of IL-1 $\beta$, IFN- $\gamma$ and TNF- $\alpha$ in lung tissues of IFV-infected mice (n=10 in each group). ${ }^{\#} P<0.01$ vs. Normal-C, ${ }^{*} P<0.05,{ }^{* *} P<0.01$ vs. IFV-C.

Fig. 8. Immunostaining microphotographs of NF-kB p65 proteins in the lung tissues of IFV-infected mice (magnification $200 \times$ ). (A) Normal control group; (B) IFV control group; (C) infected mice treated with moroxydine $(0.25 \mathrm{~g} / \mathrm{kg})$; (D) infected mice treated with YHPG (7.5 g/kg); (E) infected mice treated with YHPG (15 g/kg); (F) infected mice treated with YHPG $(30 \mathrm{~g} / \mathrm{kg})$. 
Fig. 9. Immunohistochemical analysis of NF- $\mathrm{kB}$ p65 in the lung sections ( $\mathrm{n}=10$ in each group). (A) Normal control group; (B) IFV control group; (C) infected mice treated with moroxydine $(0.25 \mathrm{~g} / \mathrm{kg}$; (D) infected mice treated with YHPG (7.5 g/kg); (E) infected mice treated with YHPG (15 g/kg); (F) infected mice treated with YHPG(30 g/kg).

${ }^{\#} P<0.01$ vs. Normal-C, ${ }^{*} P<0.05,{ }^{* *} P<0.01$ vs. IFV-C. 


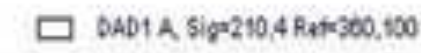

TN ? IHPG

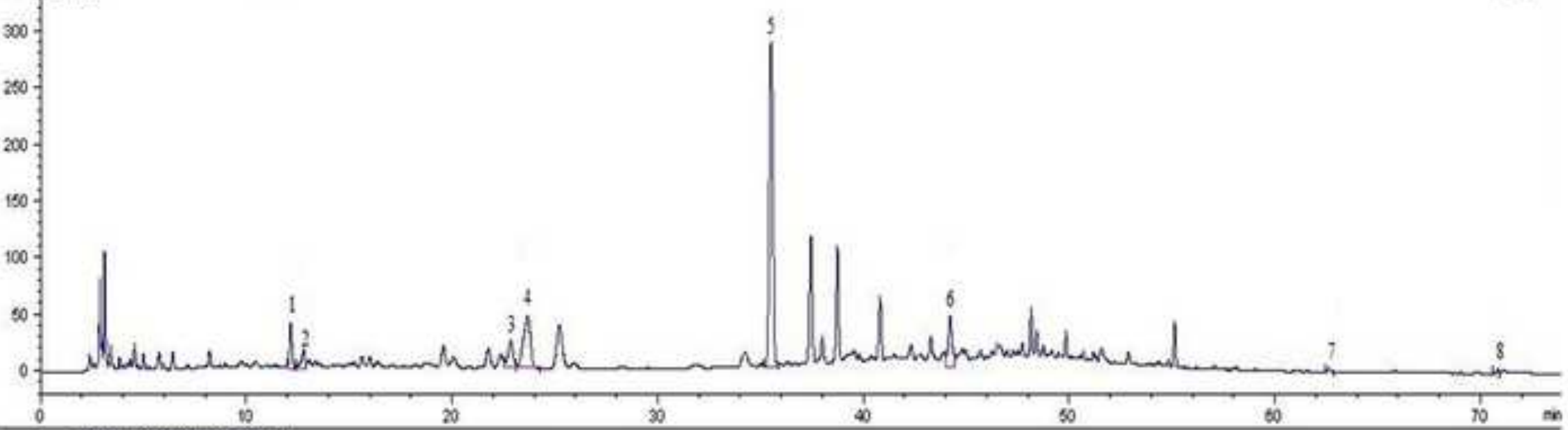

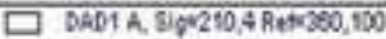

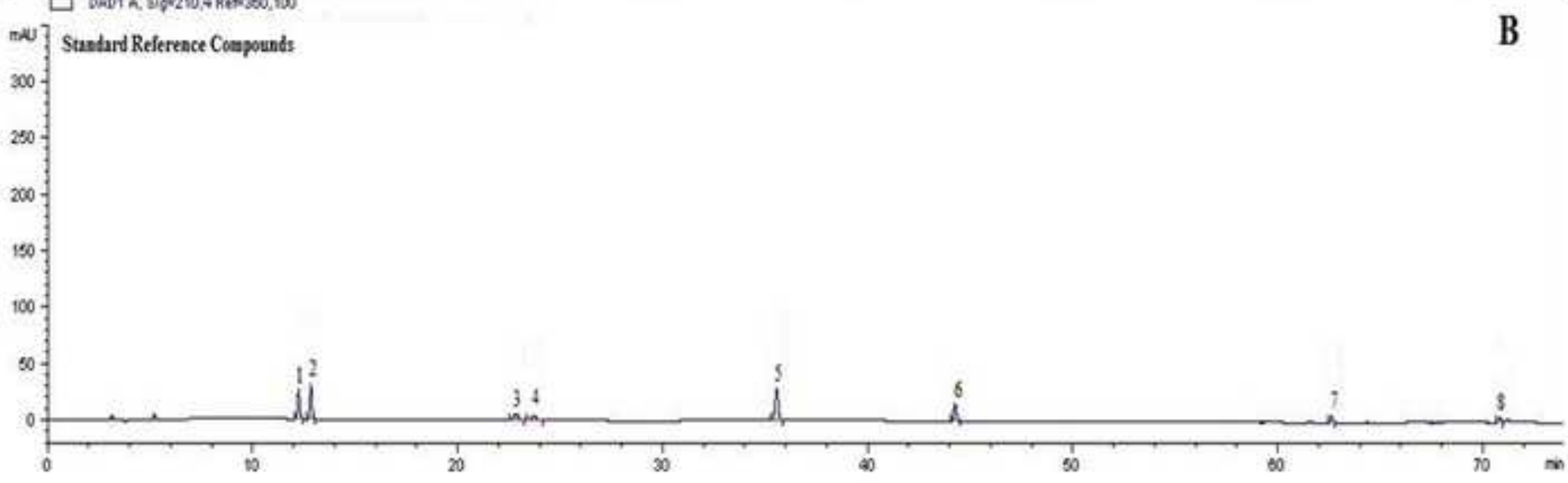


<smiles>CNC(C)[C](O)c1ccccc1</smiles>

1-ephedrine (1R, 2S)

d-pseudoephedrine (1S. 2S)

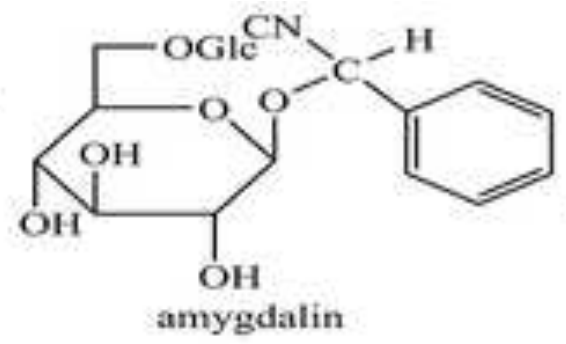<smiles>Cc1cc(O)c2c(c1)C(=O)c1cc(O)cc(O)c1C2=O</smiles><smiles>O=C(/C=C/c1ccc(O)c(O)c1)OC1CC(O)(C(=O)O)CC(O)C1O</smiles>

chlorogenic acid

$$
\text { puerarin }
$$

$\mathrm{COOH}$<smiles>O=C(O)C1OCC(O)C(O)C1O</smiles>

glycyrrhizic acid<smiles>OCC1OC(Oc2cc(O)cc(/C=C/c3ccc(O)cc3)c2)C(O)C(O)C1O</smiles>

polydatin 


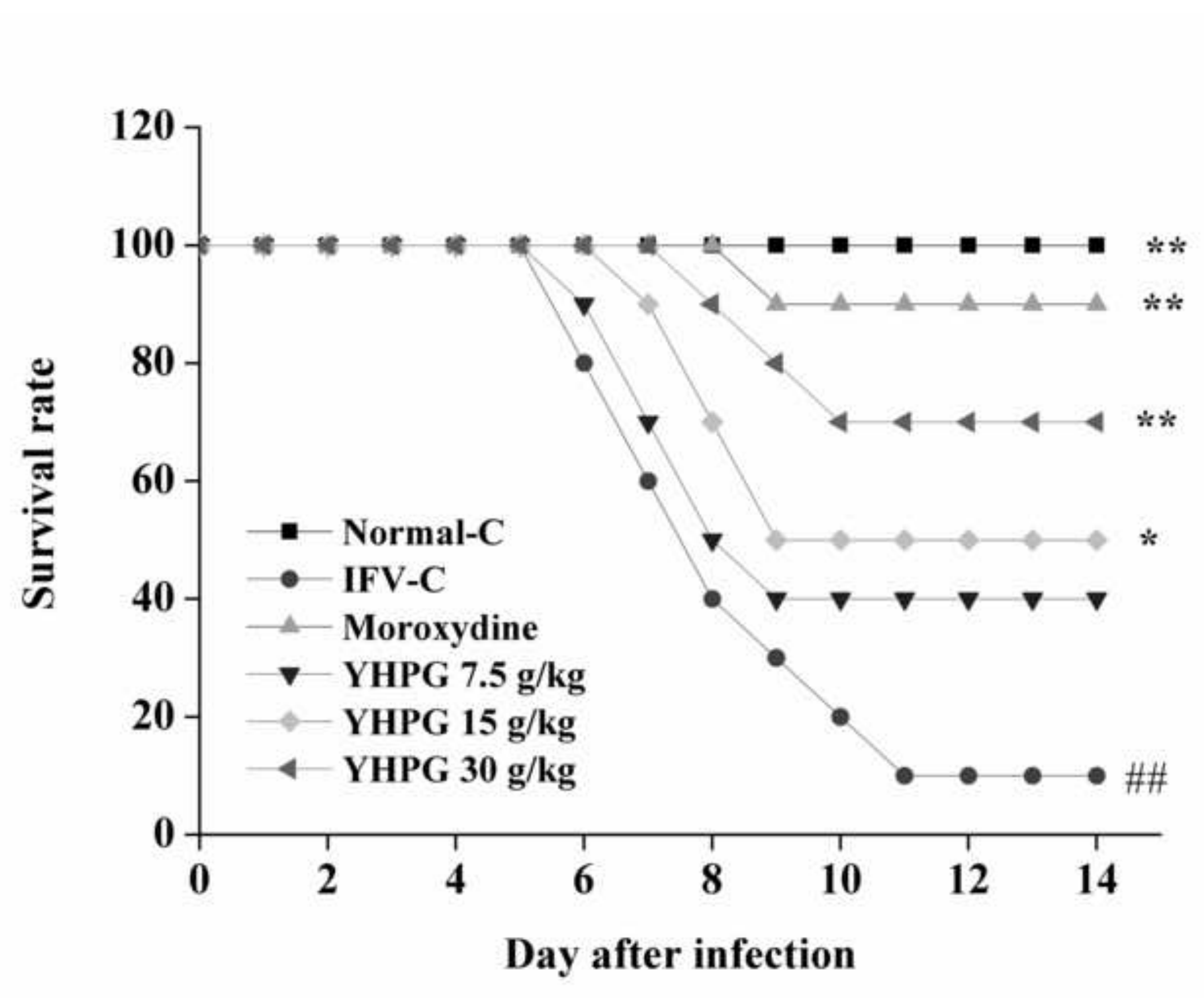

.

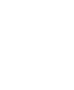

.
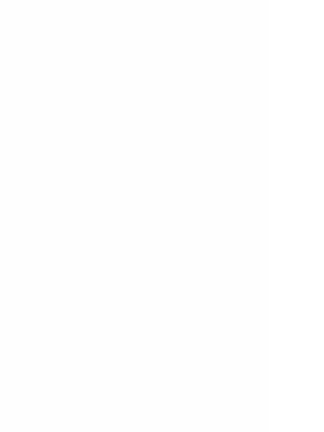


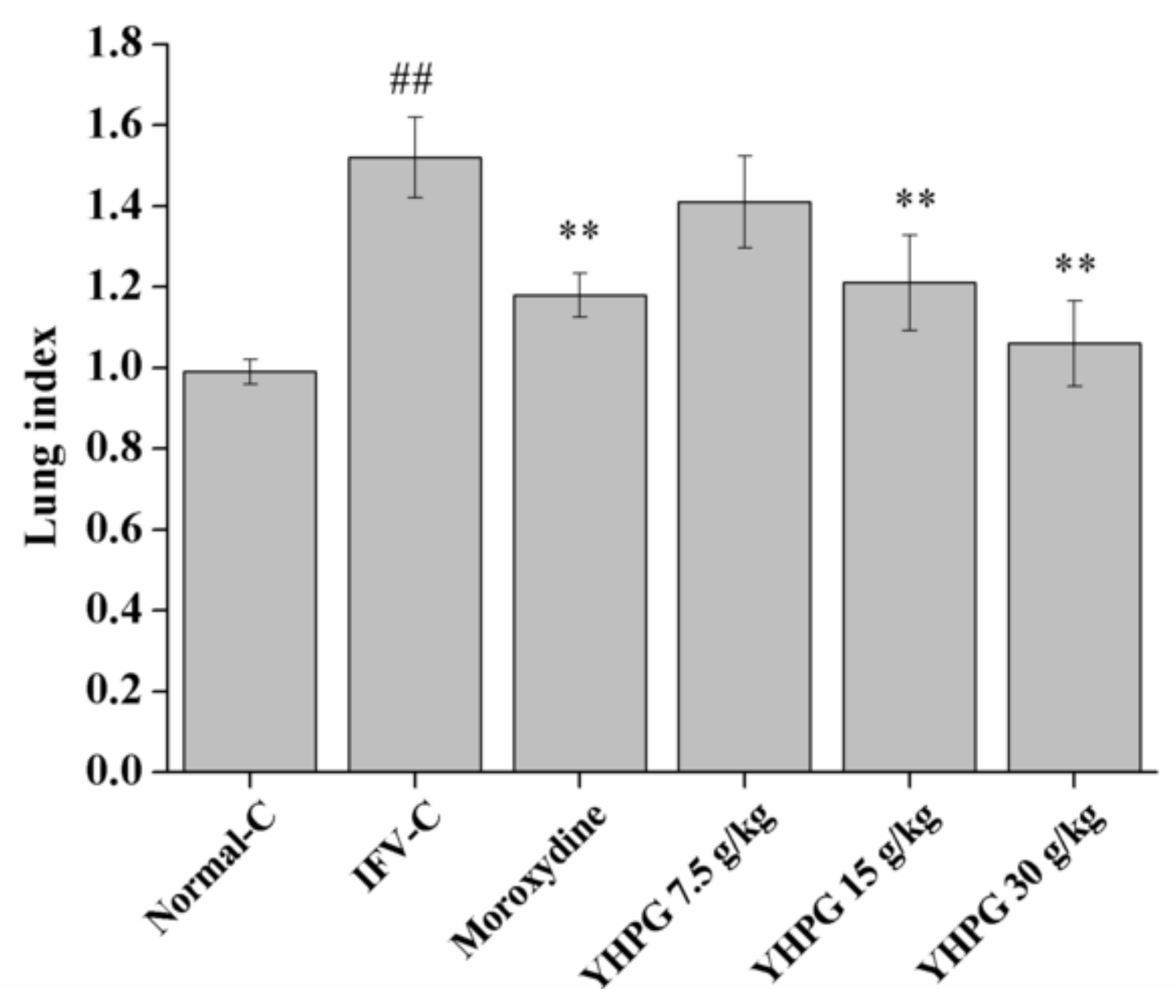


A

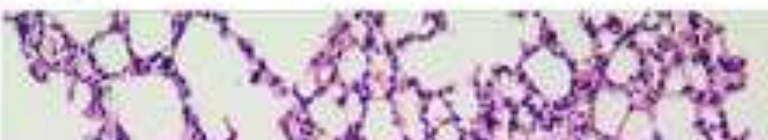
\&. P. P.

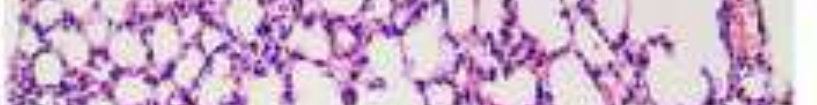

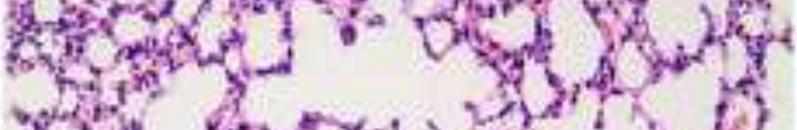

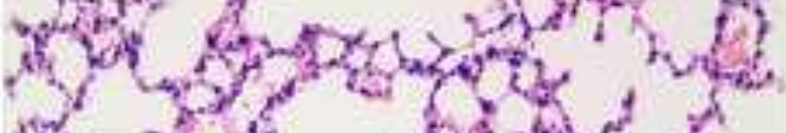

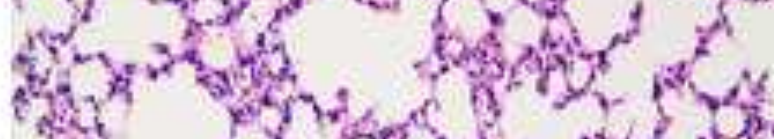

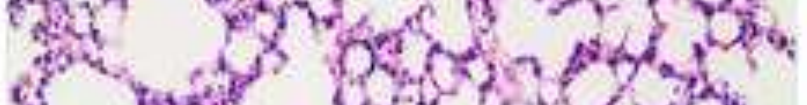

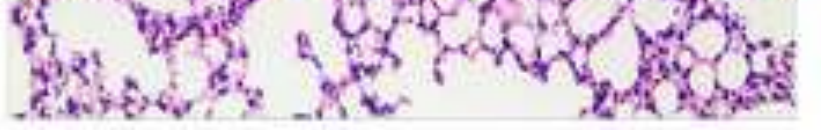

\section{D}

DFin:

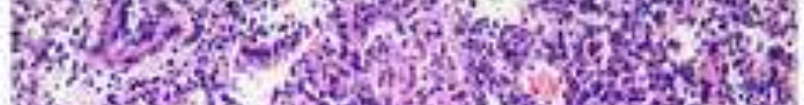
2.1.

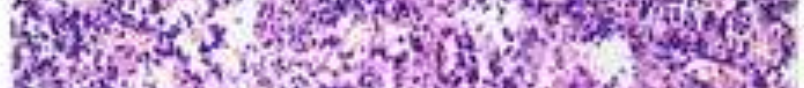

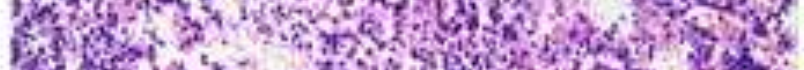

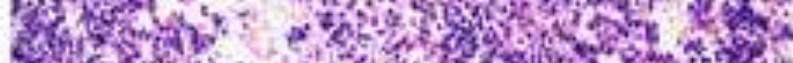

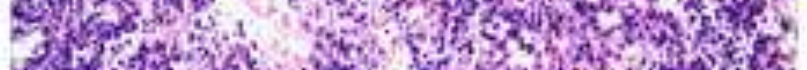
50.50 .

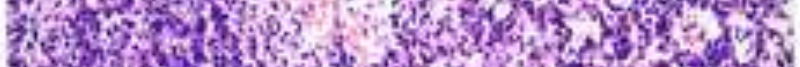

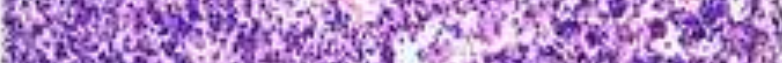

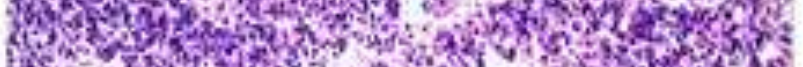

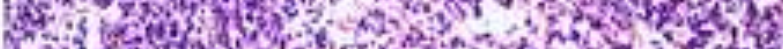

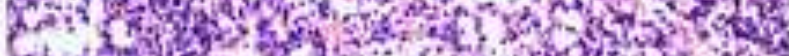
6. 3.
B

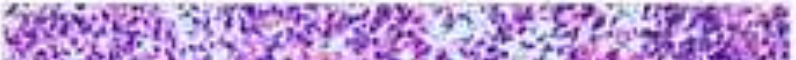
af

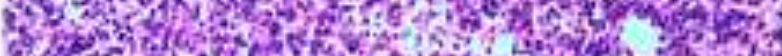

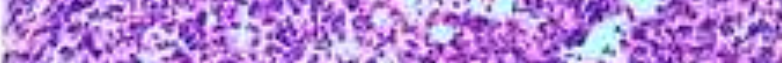

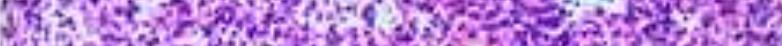

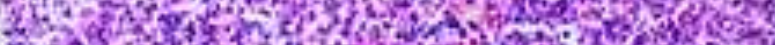

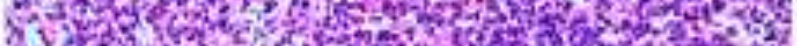

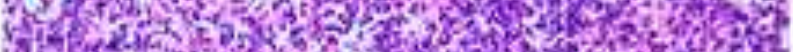

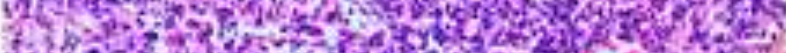

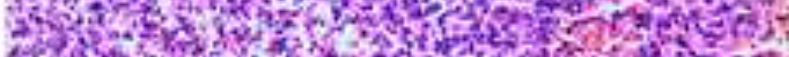

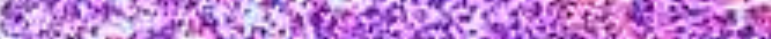

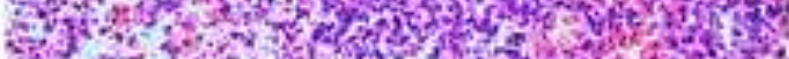

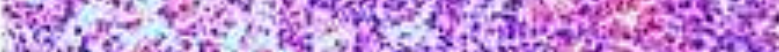
30 as 4720 ,

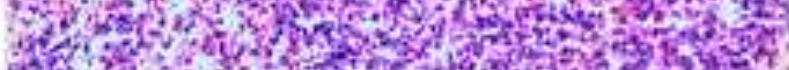

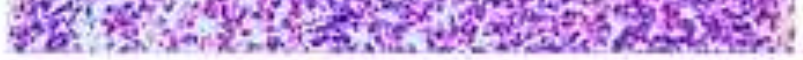

\section{E}

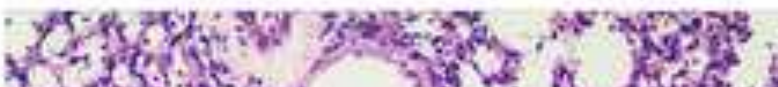

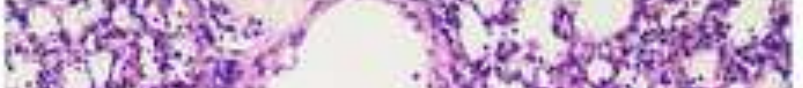

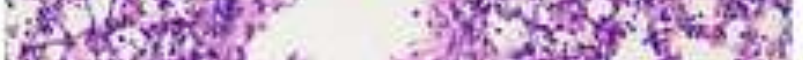
H.t.

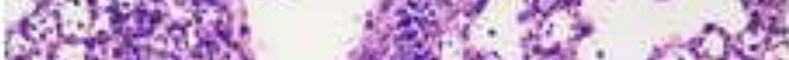

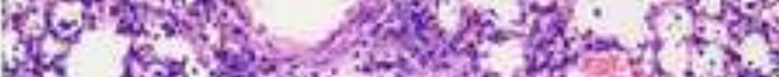

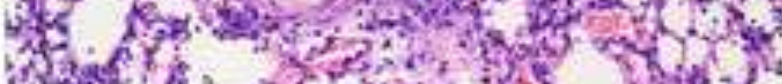

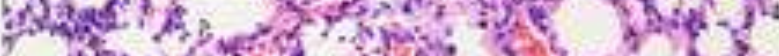

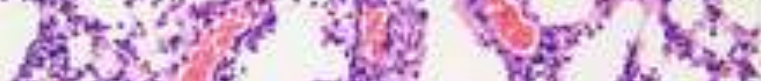

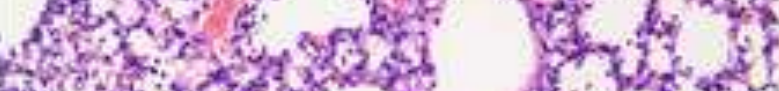

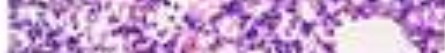

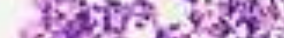

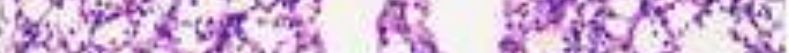

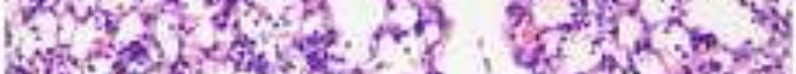
3)
C

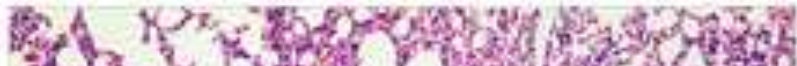
$x^{2}=2$ in ${ }^{2}$.

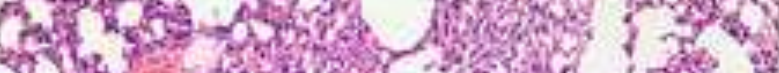

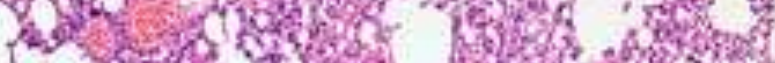

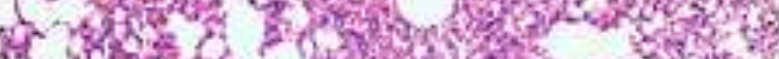

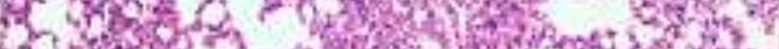

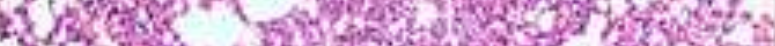

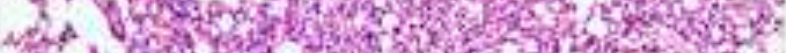

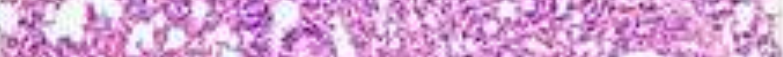

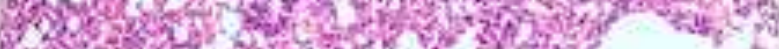

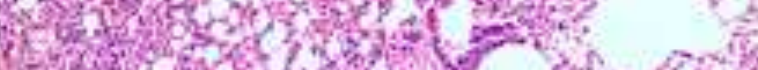

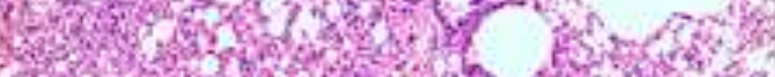

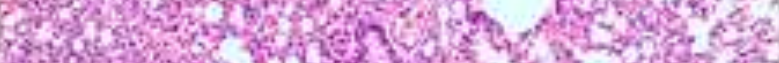

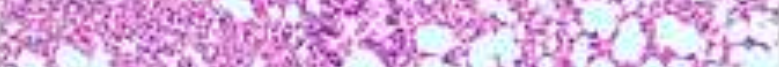

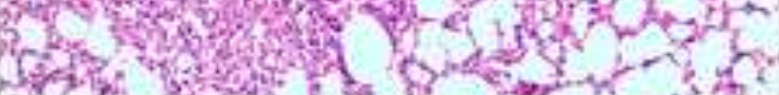

$\mathrm{F}$

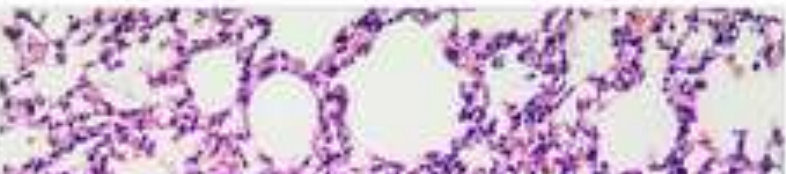
सx is $x^{2}-5$ का bु

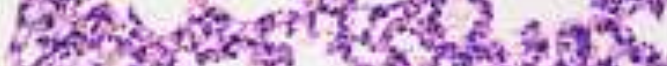

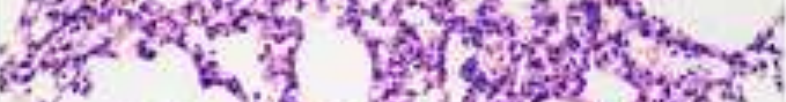

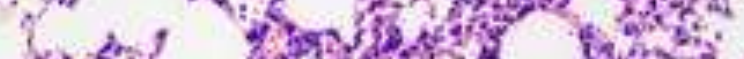

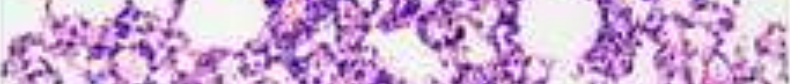

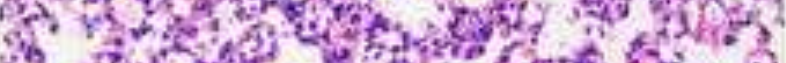

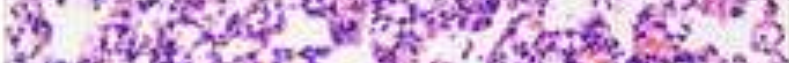

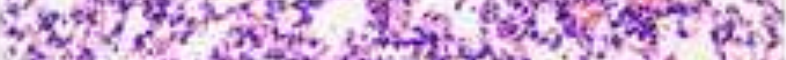

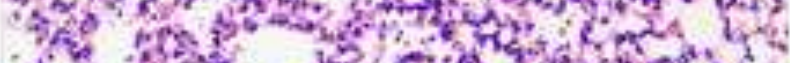

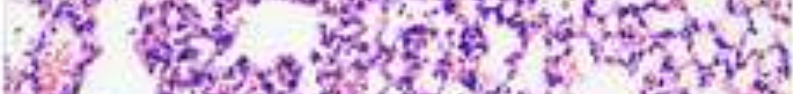

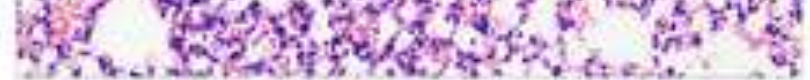



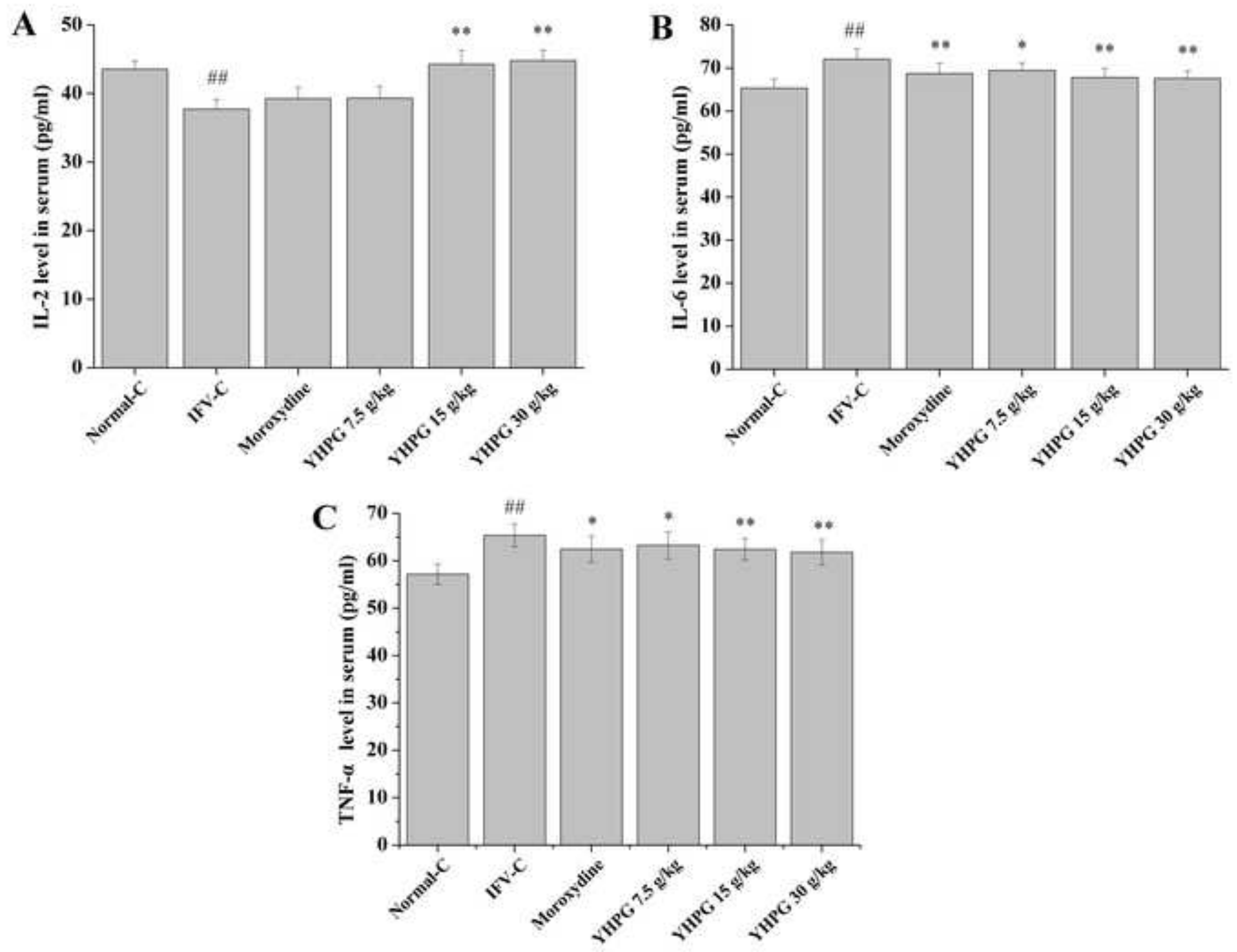


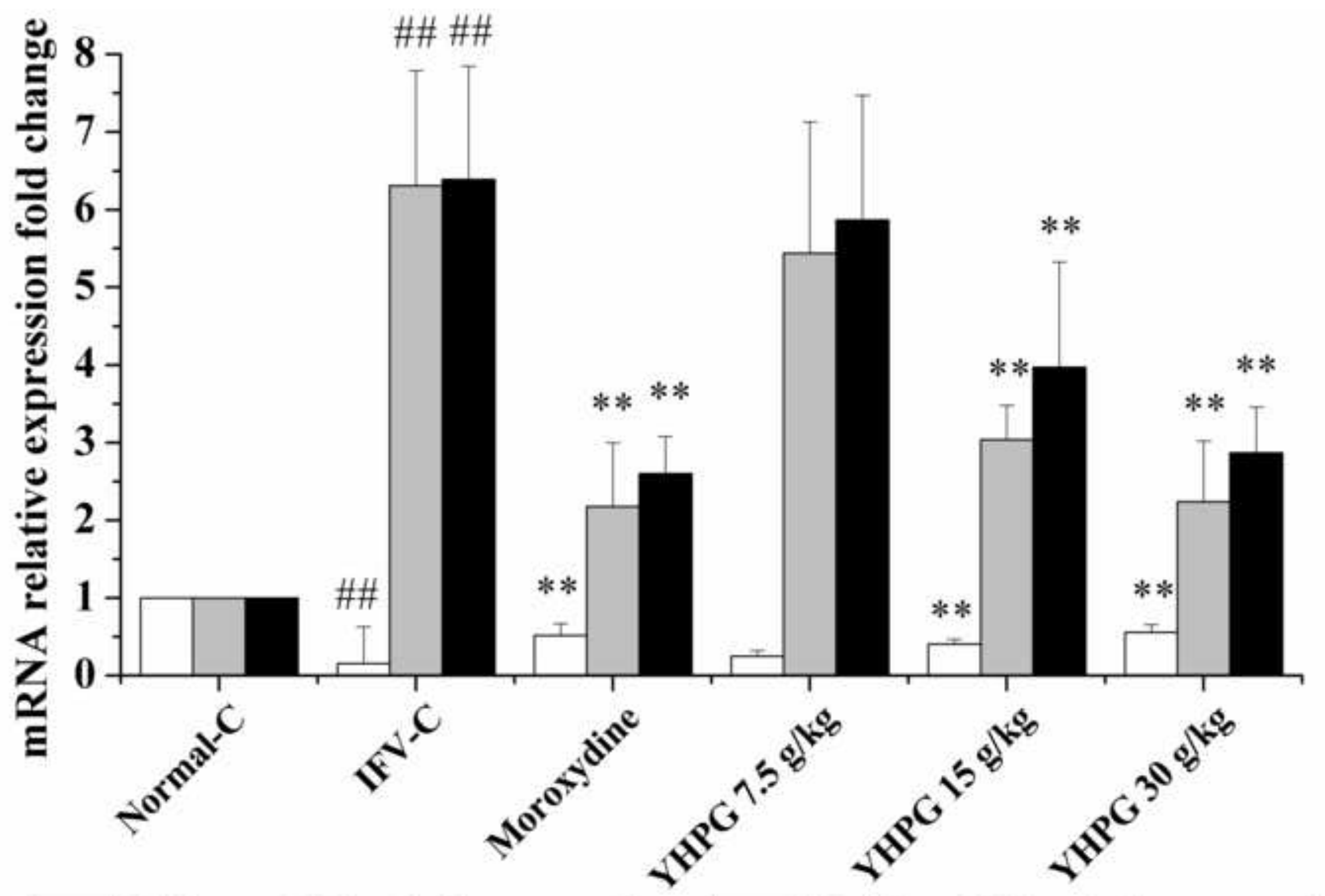

$\square$ IFN- $\gamma \quad$ mRNA relative expression

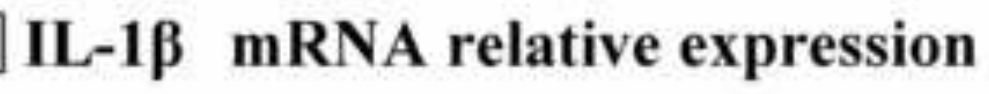
TNF- $\alpha$ mRNA relative expression 
A

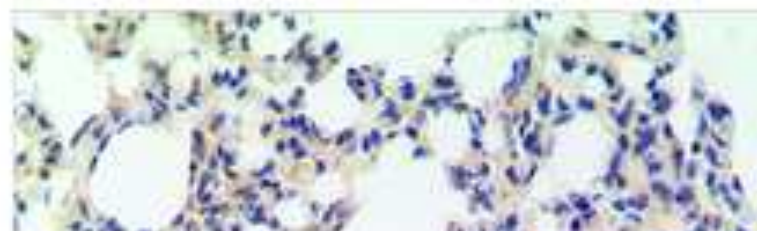

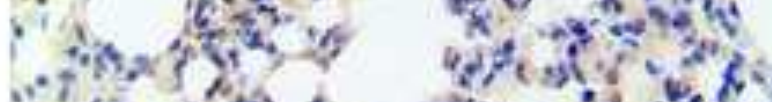

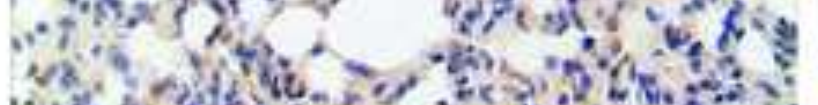
itio s.

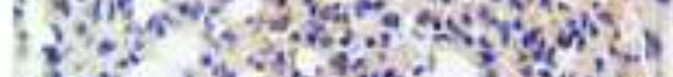

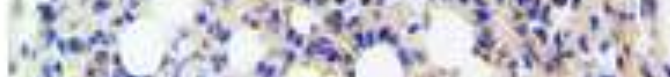

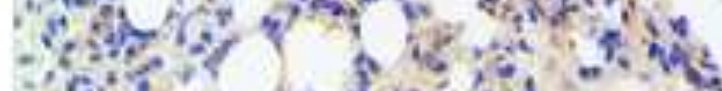

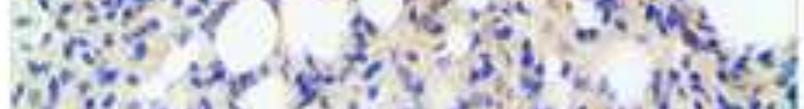
fotisos?

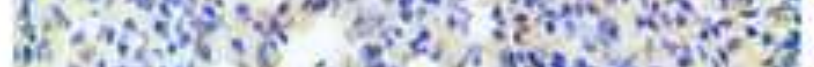

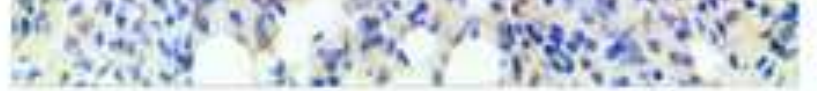

D

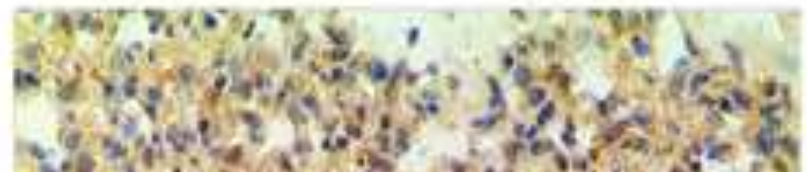
of

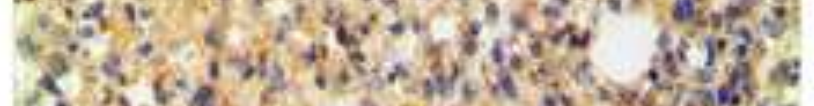

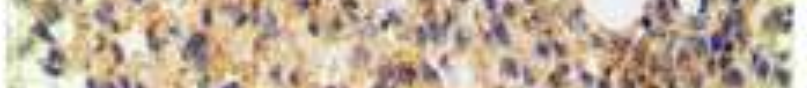

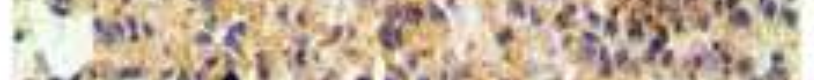
rof

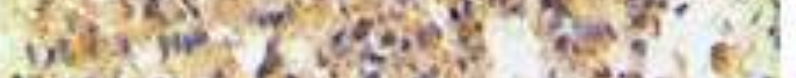
D.

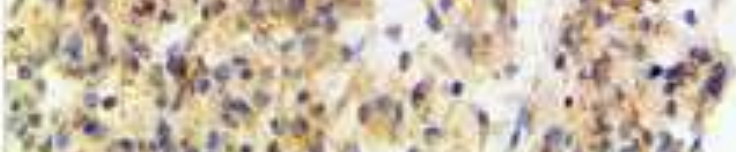

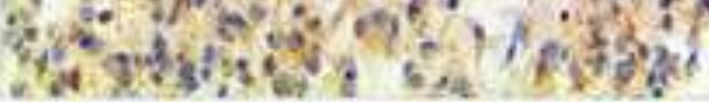

\section{B}

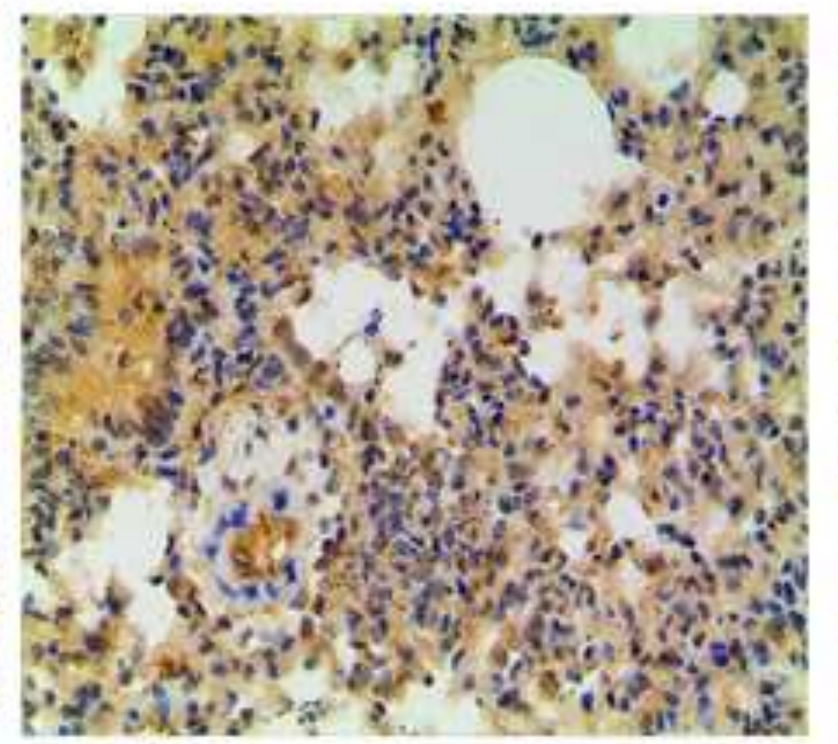

E

S.

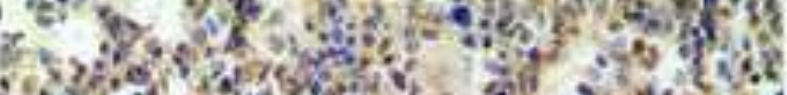

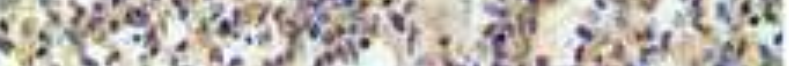

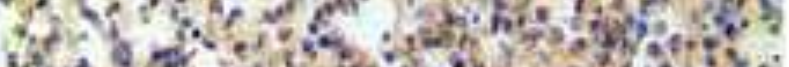

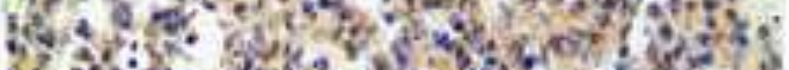
fi.

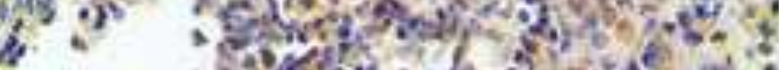

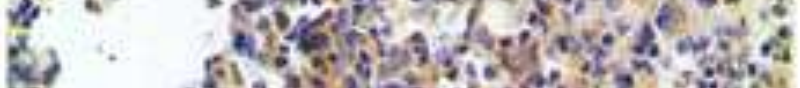

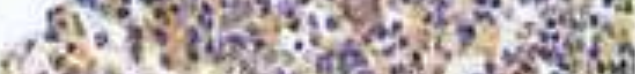

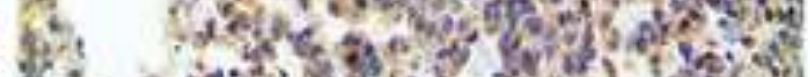

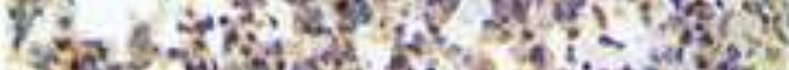

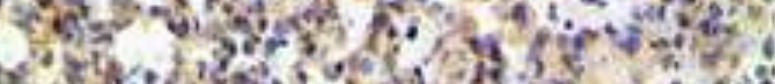

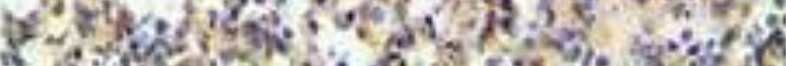

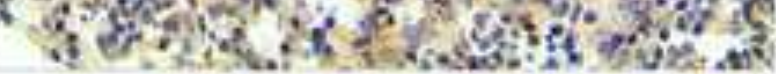

C

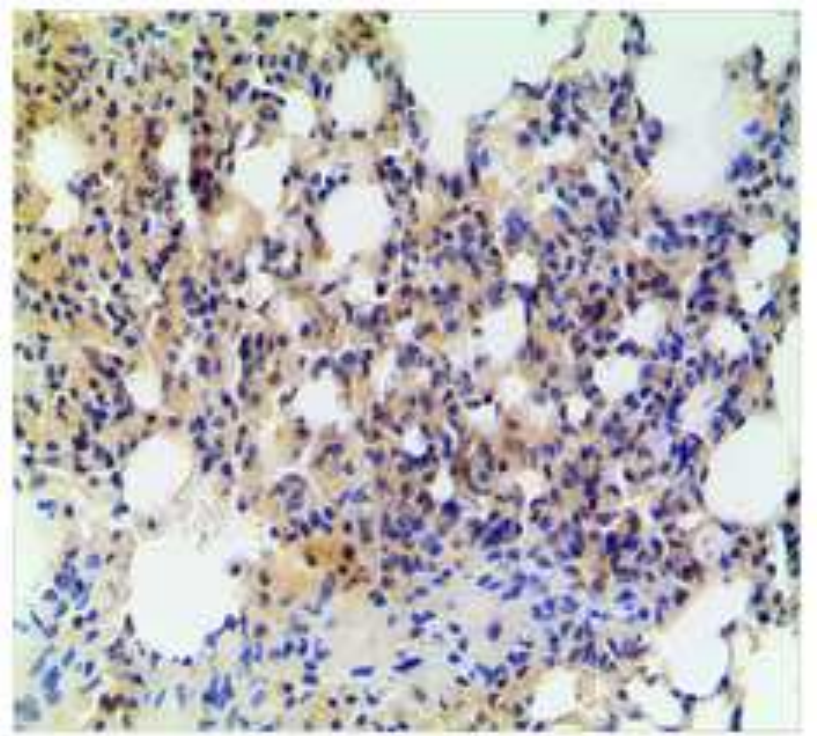

F

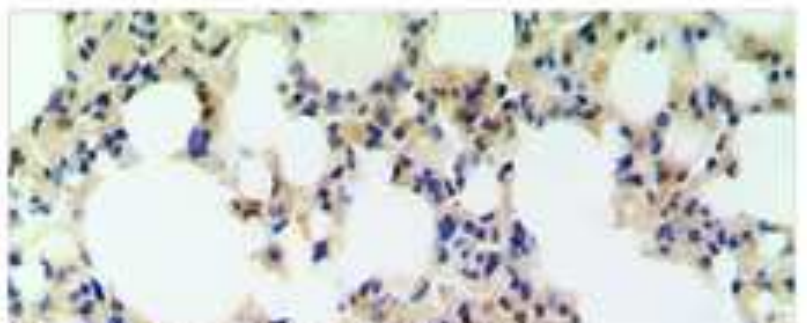

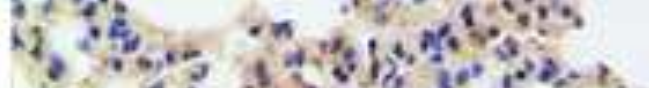

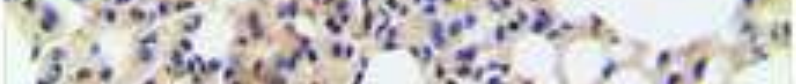
s.9.

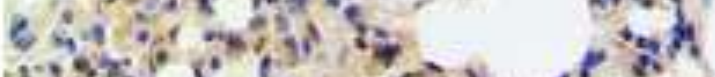

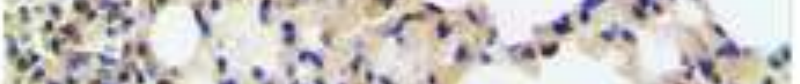

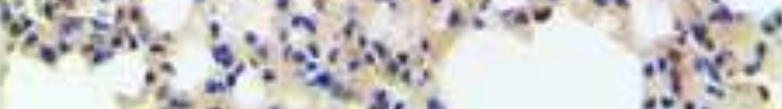

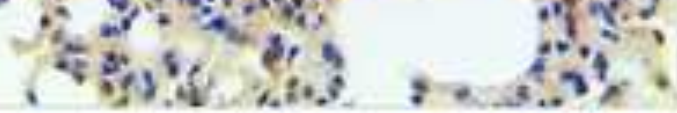




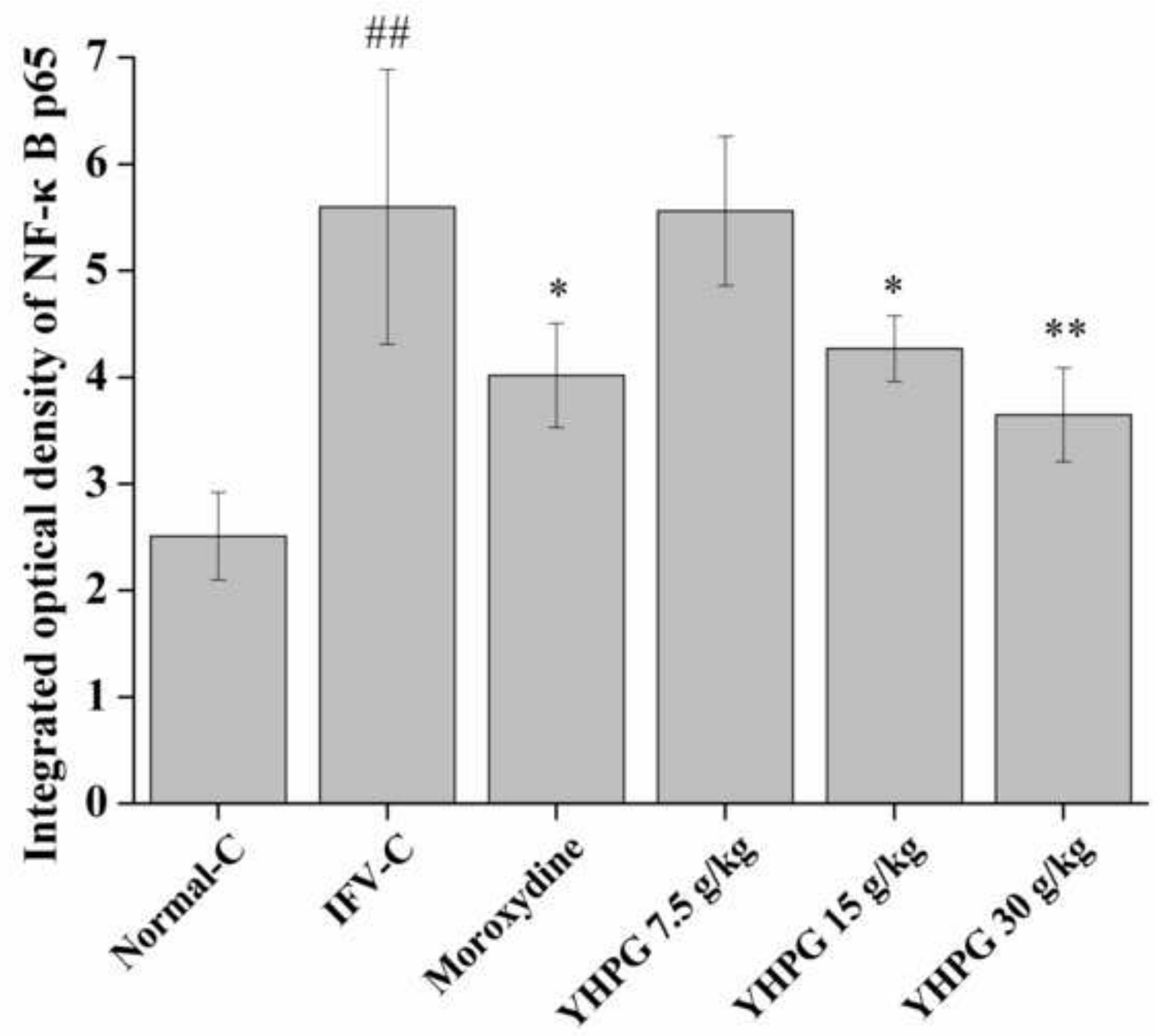

